\title{
CONCEITO DE BIBLIOGRAFIA, OU CONCEITOS DE BIBLIOGRAFIA?
}

\section{CONCEPTO DE BIBLIOGRAFÍA, O CONCEPTOS DE BIBLIOGRAFÍA?}

Marilda Lopes Ginez de Lara²

\begin{abstract}
RESUMO
Introdução: Bibliografia é um termo polissêmico que nomeia produtos, atividades e campo disciplinar. Suas inúmeras facetas não conduzem necessariamente a um conceito único e consensual. Objetivos: Procuramos discutir o conceito de bibliografia examinando as origens do trabalho bibliográfico, as relações entre o termo, o conceito e suas definições ao longo do tempo, sua tipologia e função de mediação, e as reflexões sobre a constituição de um campo disciplinar autônomo. Metodologia: Tem como base o levantamento bibliográfico, a comparação das reflexões e a tentativa de construir uma breve sistematização. Resultados: Embora exista variação denominativa e conceitual, há relativo consenso sobre o conceito de bibliografia cujo significado nuclear gira em torno dos repertórios de livros e, mais recentemente, de documentos em geral. São enfatizados aspectos técnicos das práticas bibliotecárias, como também livreiras, aspectos comunicacionais, socioculturais e historiográficos. Algumas propostas de reivindicação da autonomia do campo argumentam a favor bibliografia como disciplina matriz a partir da qual se organizam outras disciplinas correlatas. Conclusões: A bibliografia é um mecanismo especial de memória secundária cujo princípio básico se mantém apesar das tecnologias. Caracteriza-se pela produção de listas organizadas sob diferentes arranjos e pela proposta de metodologias de descrição. A emergência de um modelo pós-moderno de ciência coloca em questão a propriedade da demanda de um campo autônomo quando se prioriza o enfoque de universos temáticos à luz de óticas inter e transdisciplinares.
\end{abstract}

Descritores: Bibliografia. Conceito de bibliografia. História da bibliografia. Ciência da informação.

\footnotetext{
1 Texto base da conferência inaugural do 4o. Seminário Internacional A Arte da Bibliografia: relações histórico-epistemológicas entre Bibliografia e Biblioteconomia, Vitória, ES, dez. 2017.

2 Professora do Programa de Pós-Graduação em Ciência da Informação da ECA-USP. Bolsista de Produtividade em Pesquisa, CNPq. E-mail: larama@usp.br
} 


\section{INTRODUÇÃO}

$\mathrm{Na}$ vertente da terminologia comunicacional, bem como da socioterminologia, um conceito nunca é algo fechado e definitivo. Os conceitos são propostas que se ligam a teorias, a perspectivas, a ideologias que vão se modificando com o tempo. A resposta à pergunta "Conceito de bibliografia, ou conceitos de bibliografia?", então, tem de ser no plural e, mais ainda, 'plural'. A provocação colocada pela pergunta é apenas um mote para iniciar o debate em torno do tema 'Bibliografia' a partir das inúmeras facetas possíveis de abordagem do tema. Não pretendemos, portanto, chegar a um conceito unívoco e muito menos postular a possibilidade de um consenso.

O breve mapeamento que nos propusemos a realizar não é nem exaustivo, nem tem a profundidade necessária para dar conta da importância do tema. A identificação das várias formas de manifestação da bibliografia também não é nova. Nosso objetivo é procurar entender um pouco sobre o tema e levantar questões para o debate. Se um trabalho diacrônico permite identificar as variações da forma significante e do significado do termo ao longo do tempo, só uma visão sincrônica permite refletir sobre as características de cada abordagem, seus objetivos e motivações institucionais.

Bibliografia é um termo polissêmico utilizado para nomear um produto, uma atividade, um campo disciplinar. A abordagem dessas distintas manifestações requer uma perspectiva historiográfica, de modo a mostrar que os conceitos, os termos, sua evolução no tempo e sua situação atual não são construções isoladas, mas fruto das condições socioculturais em que foram (e são) gestados e utilizados. Interessa-nos explorar o conceito no rol das atividades documentárias procurando indicar as distinções que privilegiam essa abordagem em face à de cunho mais comercial e buscando identificar o que junta ou separa os conceitos. Procuraremos, também, introduzir a discussão sobre a situação da bibliografia frente às alterações advindas das novas tecnologias e sobre os problemas da circunscrição de um campo autônomo no momento contemporâneo. 


\section{O QUE É BIBLIOGRAFIA?}

\subsection{Origens do trabalho bibliográfico}

A paternidade da bibliografia ou dos repertórios bibliográficos é motivo de muita discussão, não havendo consenso entre os pesquisadores. É inegável que esse tipo de documento existiu, sob a forma de manuscritos, na Antiguidade (Cassiodoro, Calímaco) e na Idade Média. Sob a forma impressa, as bibliografias e repertórios apareceram depois de 1494, recebendo inúmeras denominações, como biblioteca, catálogo e repertório ${ }^{2}$ (BOUSTANY, 2007, online).

A primeira bibliografia sistemática publicada, Liber de scriptoribus ecclesiasticis (1494), é de autoria de Johannes Trithemius (1462-1516), considerado um dos pais da Bibliografia na Idade Moderna. Apesar do título, essa bibliografia não se restringe às obras de escritores eclesiásticos no sentido estrito, mas no âmbito da civilização cristã incorpora escritos filosóficos, científicos e literários (SERRAI, 1997, citado por ARAUJO, 2015).

Mais especificamente, a origem do repertório bibliográfico é identificada no final do séc. XV e ao longo do século XVI, algumas décadas depois da invenção da imprensa por Gutemberg (BOUSTANY, 2007). O trabalho de Gesner, com a Bibliotheca Universalis, é uma referência praticamente unânime. Luigi BALSAMO (1998) é crítico em relação à atribuição do nascimento da bibliografia ao aparecimento da imprensa, uma vez que a necessidade de ter informação sobre a produção literária em geral já existia. O que teria ocorrido seriam alterações estruturais no setor da informação com efeitos no plano cultural, assim como aconteceu em seguida com a revolução industrial e a evolução eletrônica, quando o livro teria perdido a centralidade ou predomínio instrumental que durou séculos. "[...] antes de se chamar bibliografia, 0 repertório teve outros nomes, entre eles o metafórico biblioteca que predominou por quase três séculos" (BOUSTANY, 2007, p. 15), o que

\footnotetext{
${ }^{2} \mathrm{~A}$ tradução dos textos originais em francês, italiano e inglês são traduções livres.
} 
demonstra uma estreita relação entre a coleta de informações e sua organização. A história da bibliografia, portanto, não acabou.

\subsection{Termo/ Conceito/Definição}

Do ponto de vista etimológico, a palavra bibliografia, de origem grega, corresponde a "biblion = livro e 'graphein' = escrever, e é posterior ao objeto que designa: o repertório de títulos" (BOUSTANY, 2007).

O surgimento do termo bibliografia é atribuído a Gabriel Naudé (1627) e a Louis Jacob, em 1643, (BOUSTANY, 2007; BALSAMO, 1998). O termo não teve muita ressonância na época de Naudé, sendo pouco usado pelos contemporâneos. Sua Bibliographia política (1633), elaborada a partir de um pedido de uma nomenclatura de livros e escritores, constitui uma exposição crítica das obras, não só porque Naudé não tinha os livros ao seu alcance, como também porque queria fazer algo bem distinto de uma simples lista de livros. Como não se tratava de um repertório habitual e era uma obra diferente no âmbito do que se denominava 'história literária', Naudé preferiu não usar o termo Bibliotheca, optando por Bibliographia (BALSAMO, 1998).

O termo reapareceu na sua forma original com a publicação da Bibliographia parisina em 1645, com Louis Jacob, amigo e seguidor de Naudé, para contemplar o sentido de "[...] dar notícia dos livros mais recentemente impressos em uma determinada área geográfica” (BALSAMO, 1998, p. 98). Como no caso da Bibliographia política de Naudé, Jacob julgou que o termo bibliotheca, enquanto coleção orgânica de livros relativos a autores e seu conteúdo, não se aplicava, pois se tratava de um "catalogus librorum" cujos livros não pertenciam a uma biblioteca, nem a um catálogo de livreiro. Mas ocorreu o mesmo com Jacob: novamente o termo bibliografia não teve muita aceitação. Nos dois casos, temos exemplos de bibliotecas extramuros.

O uso do termo bibliografia, porém, só se generalizou no século XIX quando passou a constar dos títulos dos repertórios. Boodson cita Besterman que, ao descrever a origem das bibliografias, fala das organizadas, por volta do ano 1500, como listas de trabalhos de um autor feitas pelo próprio autor e incluídas em um dos seus trabalhos posteriores (BESTERMAN, 1935, citado por BOODSON, 1976). 
Depois da Revolução Francesa, com o desenvolvimento da atividade bibliográfica, ela assumiu um sentido genérico. O confisco de grandes coleções gerou, no Estado, a necessidade de reuni-las e organizá-las de algum modo. "A bibliografia se torna a ciência do livro sob todos os seus aspectos" (BOUSTANY, 2007). Para a autora, a definição que consta na Grande Encyclopédie de Berthelot, publicada em 1885, corrobora esse sentido: "a ciência dos livros do ponto de vista de sua descrição e classificação" (2007). A definição é alterada por Gabriel Peignot, em 1802, quando da publicação do Dictionnaire raisonné de Bibliologie, que nomeou a ciência do livro, Bibliologia, e "fez da bibliografia um de seus ramos que se ocupa dos repertórios de livros" (2007).

A divisão é também citada por Couzinet (2012) reportando-se a Peignot. Conforme retoma Ortega, apoiando-se em Couzinet, a bibliografia, enquanto ramo da bibliologia, estaria "voltada aos aspectos técnicos e à elaboração de repertórios de livros" (ORTEGA, 2016, p. 41), enquanto a bibliologia "envolveria o estudo histórico e científico do livro e os conhecimentos filosóficos, históricos e literários relativos à bibliografia" (2016, p. 42). Os dicionários da época tendem a reproduzir essa definição até aproximadamente o ano de 1934 (BOUSTANY, 2007).

Uma definição mais exata foi proposta, em seguida, por Louise-Noëlle Malclès, em 1956, sublinhando a importância, na história das bibliografias, das circunstâncias que condicionaram a produção dos repertórios. Malclès construiu um quadro diacrônico procurando ligar a produção dos repertórios às características culturais de cada momento: na sequência, "época humanística, histórica, científica, bibliofílica [1790-1810], artesanal [1810-1914], técnica [depois de 1914], com um capítulo final dedicado às bibliografias de bibliografias" (BALSAMO, 1998, p. 187-188). Malclès realizou um estudo profundo e crítico da bibliografia, ressaltando a necessidade e a complexidade da pesquisa historiográfica, conforme se comprova a seguir:

Estabelecer relações entre a atividade dos bibliógrafos e as necessidades da pesquisa intelectual nas distintas épocas, determinar para cada época as relações entre os fatores históricos, econômicos, etc. e a publicação dos repertórios, e destacar, finalmente, as correntes de influência entre uma e 
outra nação poderiam ser os objetivos de um estudo científico geral (MALCLĖS, 1956, citada por BALSAMO, 1998, p. 14).

Antes de repertoriar várias propostas de definições, Balsamo destaca o que, para ele, é mais importante do ponto de vista histórico: a dimensão cultural da bibliografia e, mais especificamente, sua "[...] função institucional precisa, desenvolvida dentro do sistema de difusão da cultura" (BALSAMO, 1998, p. 12). A bibliografia seria, primeiramente, um instrumento ou veículo de informação que desempenha uma função positiva ou negativa, conforme a intenção de fazer circular ou restringir o uso dos livros (a mediação positiva ou a mediação negativa). Ela desempenharia um papel importante na formação das bibliotecas públicas ou privilegiaria a técnica de descrição dos livros para alcançar objetivos bibliofílicos, mais econômicos do que culturais propriamente ditos. Em todos os âmbitos sua função primordial seria dar a conhecer os livros via difusão e, consequentemente, compor a história da cultura (1998).

Segundo Balsamo (1998), na segunda metade do século XVI, a história da cultura na Idade Média orientou-se por dois modelos opostos baseados em diferentes interpretações da função social da cultura: de um lado, a visão segundo a qual a dignidade do homem reside na busca responsável e racional da verdade e, de outro, a visão dogmática de quem se enxerga como portador de verdades indiscutíveis. Derivam daí as diferenças na concepção da difusão cultural com efeitos não só na seleção da bibliografia, na memória documentada nas bibliotecas e na biblioteca, ela mesma, como serviço público. Mas bibliografia também foi definida como técnica de descrição catalográfica e de classificação bibliotecária. O autor também se refere a outras definições destacadas da literatura recente, a exemplo da definição técnica de Schneider, em 1936, para quem a bibliografia seria o estudo dos modos de preparação de repertórios ou listas de livros, e a de Walter Greg [1875-1959], que privilegiaria o "estudo do livro enquanto objeto material", a que corresponderia uma 'bibliografia crítica' ou 'analítica' (BALSAMO, 1998, p. 186). As duas definições contemplam mais a prática dos livreiros e editores, do que o sentido privilegiado pela bibliografia identificada como repertorial.

As vertentes repertorial e material distinguem-se pelas características que priorizam. A bibliografia repertorial dedica-se a buscar, identificar, 
descrever e classificar os documentos para organizar repertórios; a bibliografia material ou bibliografia analítica, que se desenvolveu no âmbito anglo-saxão, volta-se ao estudo das técnicas de produção do livro nos aspectos histórico, descritivo, analítico e crítico (REYES GÓMEZ, 2005, citado por ARAUJO; REIS, 2015).

Greg, segundo Capaccioni (2006, p. 16), irritava-se ao verificar que as definições no início do século XX se resumiam a identificar a bibliografia como uma atividade de produzir listas, insistindo sobre o fato de que a disciplina deveria "ocupar-se do livro como objeto, da análise de seus processos produtivos e da descrição analítica do exemplar".

A definição de Theodore Besterman, em 1935, se opõe à de Greg, assinalando que uma bibliografia deve ser conduzida por um "princípio constante", a partir do que estariam excluídos os catálogos de bibliotecas e os de livreiros. À procura de precisão, mostra como a palavra bibliografia pode ser considerada como uma 'mot-valise', uma palavra que acomoda vários sentidos. A definição que concerne ao trabalho com a informação é a relativa à "bibliografia de informação científica usada para localizar conhecimento publicado sobre um assunto" (BOODSON, 1976, p. 16), ou seja, uma fonte secundária.

Para Balsamo, num outro plano, numa outra época e em áreas nacionais diferentes, os livreiros assumiram papel protagonista na bibliografia. Além dos aspectos econômicos que têm diferenças se comparados aos relacionados à difusão cultural, o termo bibliografia teria sofrido, nesse caso, uma mudança semântica, passando a indicar, além de 'conhecimento dos livros', a 'técnica de descrição dos livros' (BALSAMO, 1998, p. 13), particularmente dos livros raros de interesse para o mercado bibliófilo. Embora essas iniciativas tivessem influenciado mais diretamente a formação das bibliotecas privadas, elas acabaram confluindo, depois, para as grandes bibliotecas públicas modernas. De um modo ou outro, a bibliografia teve (e tem) um papel importante na história do livro, contribuindo para "traçar itinerários e modalidades da circulação dos livros [...]."

A bibliografia tem o dever, precisamente, de coordenar e utilizar o saber para obter proveito dele, dando a conhecer os livros e promovendo sua difusão; 
em consequência, é um componente importante da história da cultura (BALSAMO, 1998, p. 13).

Levantamento realizado por Capaccioni em dicionários, enciclopédias e glossários da área de Biblioteconomia, Documentação, Ciência da Informação publicados em vários países ${ }^{3}$ - "La bibliografia: materiali per um esame comparato dei termini fondamentali" (CAPACCIONI, 2014) mostra que,

[...] embora persistam dúvidas sobre a natureza da disciplina, identificada na pergunta frequente 'O que é a bibliografia', $O$ vocabulário utilizado é razoavelmente consensual e segue a interpretação de Theodore Besterman, como uma lista de livros ordenados sob um mesmo princípio informacional.

Essa interpretação, para Capaccioni (2014), tem prevalecido na literatura anglo-saxã, tal como aparece no ODLIS - Online Dictionary for Library and Information Science: uma "lista sistemática ou enumeração de obras escritas por um autor específico ou sobre um determinado assunto, ou que compartilhem uma ou mais características comuns (idioma, forma, período, local de publicação, etc.)". Outra vertente, segundo a mesma fonte, identificaria a bibliografia como "a arte e a prática de descrever livros, com especial referência à sua autoria, publicação, forma física e conteúdo literário" (ODLIS, Online Dictionary for Library and Information Science, <https://www.abcclio.com/ODLIS/odlis b.aspx> definição que foge, portanto, à perspectiva documentária.

Verifica-se, pelo exposto, que não existe uma única definição de bibliografia, nem uma única perspectiva para a delimitação da atividade. $O$ que as une é o fato de girar em torno do livro, traço nuclear presente na definição etimológica. O termo bibliografia não tem aceitação imediato, mas foi primeiramente utilizado para substituir o termo biblioteca para diferenciar 0 repertório de coleções que ultrapassavam seu limite físico. A generalização do

${ }^{3}$ (...) Diccionario enciclopédico de Ciencias de la Documentación, editor José López Yepes, Madrid Editorial Sintesis, 2004 (d'ora in poi DECID); per quella italiana il recente Biblioteconomia. Guida classificata, diretta da Mauro Guerrini, Milano, Editrice Bibliografica, 2007 (BIBGUI) e le due edizioni del Glossario di biblioteconomia e scienza dell'informazione (GLOBSI 1/2) edito a Milano dalla Editrice Bibliografica nel 1985 a cura di Giuliano Vigini e nel 2003 a cura di Ferruccio Diozzi; per l'area nord europea il Core Concepts in Library and Information Science (2005) curato da Birger Hjørland (edizione Web; CCLIS); per l'area nordamericana la decima edizione (2005) del Harrod's librarians' glossary and reference book curato Ray Prytherch (HARGLO) e l'Online Dictionary for Library and Information Science (2004) curato da J. M. Reitz (edizione Web; ODLIS) (Capaccioni, A. (2014).

Inf. Inf., Londrina, v. 23, n. 2, p. 127 - 151, maio/ago. 2018. http://www.uel.br/revistas/informacao/ 
termo se deu apenas no século XIX quando foi integrado ao título dos repertórios, ainda com um sentido não unívoco. É assumida como ciência depois da Revolução Francesa, embora o termo conhecesse variações quanto à sua abrangência: bibliografia, ramo da bibliologia quando o foco eram os aspectos técnicos de elaboração, e bibliologia para o campo mais amplo de reflexões históricas e científicas da bibliografia. É, em seguida, abordada na sua importância historiográfica, na sua dimensão cultural, mas também em relação às práticas dos livreiros e à descrição e classificação em bibliotecas. $\mathrm{Na}$ fixação dos limites do termo, há autores que também se preocupam na identificação de uma tipologia de bibliografias. Embora a variação definicional seja muito grande, há relativo consenso entre as delimitações propostas.

\subsection{Forma de Organização das Bibliografias}

Do ponto de vista do arranjo, as primeiras bibliografias eram organizadas por autor ou por ordem cronológica, destacando-se o trabalho de Gesner (1545-1555), a Bibliotheca Universalis, complementado pelo Pandectarum que é considerado o primeiro índice classificado por assunto que abrangia cerca de 15 mil títulos e 3 mil autores (BOODSON, 1976).

As bibliografias podem ser analisadas quanto ao assunto (gerais ou especializadas), ao número (exaustivas, seletivas), ao lugar (locais, regionais, nacionais, internacionais ou universais), ao tempo (retrospectivas, correntes), ao aspecto (sinaléticas, descritivas), ao conteúdo (analíticas ou anotadas, críticas). Já quanto à natureza, a bibliografia pode ser primária ou secundária (BOUSTANY, 2007).

Para Greg (1996, citado por CAPACCIONI, 2006), a bibliografia que constitui uma lista de publicações sobre determinado assunto ou autor é a bibliografia enumerativa; o estudo de uma edição, de sua produção e recepção constitui uma bibliografia analítica ou descritiva. Para Stokes (1969), a bibliografia pode ser enumerativa, analítica ou crítica, descritiva, textual e histórica. Capaccioni (2006) também cita Stokes que distinguiu cinco tipos de bibliografia: enumerativa, analítica ou crítica, descritiva, textual e histórica.

Para Madsen (1993, citado por HJORLAND, 2007), a bibliografia pode ser analisada por suas facetas: enquanto produto, é o documento que 
compreende referências a outros documentos; enquanto documento, ela pode ter cobertura universal ou internacional, nacional, ser relativa a autores, a assuntos específicos e se apresentar como catálogos.

O produto do trabalho bibliográfico é, enfim, um mecanismo particular da memória secundária da informação (BALSAMO, 1998, p.16) que pode ser organizado de distintas maneiras, como também ser objeto de estudo dos processos de produção, transmissão e recepção textual (MCKENZIE, 1999).

A proposta de tipologias de bibliografia é mais característica da identificação dos produtos da atividade bibliográfica - as bibliografias propriamente ditas, pode também se referir às formas de descrição praticadas pelos livreiros - a bibliografia material ou analítica, ou ainda, as análises resultantes da sociologia dos textos, na linha das reflexões de Mckenzie (1999).

\subsection{Constituição do Campo Disciplinar}

Os livros, quando tratados como objetos de
estudo, também se recusam a ficar confinados
dentro dos limites de uma única disciplina.
Nenhuma delas - a história, a literatura, a
economia, a sociologia, a bibliografia - é capaz de
fazer justiça a todos os aspectos da vida de um
livro. Pela sua própria natureza, portanto, a
história dos livros deve operar em escala
internacional e com método interdisciplinar
(DARNTON, 1995, p. 130-131, citado por
CRIPPA, 2016).

Diferentes teóricos contemporâneos compartilham a visão que não apenas procura recuperar a história da bibliografia, como relacioná-la fortemente à cultura e reinterpretá-la no contexto de sua manifestação. Disso deriva uma hipótese de desenho contemporâneo do campo que, na sua constituição, passou - e passa - por fases de disputa formal ou informal.

Para Capaccioni (2006, p. 11), as visões sobre a origem da bibliografia postulam, de um lado, a imprensa e, de outro, a exigência da comunicação. A pouca difusão do termo nos séculos XVII e XVIII teria sido uma das causas das dúvidas sobre os seus limites, que ficaram ainda mais confusos quando da 
mais recente comparação ou atribuição da tradicional bibliografia à documentação, sem que esta tenha chegado a substituí-la.

Para Zaher e Gomes (1972), a bibliografia foi objeto de "preocupação de estudiosos que procuraram aprimorar técnicas e métodos para melhor controlar e divulgar o material bibliográfico existente" e, com o florescimento da imprensa, seu âmbito foi ampliado para dar conta das necessidades sociais de conferir maior especificidade ao tratamento da informação. Novos especialistas e novas tecnologias passaram a ser exigidos, levando ao aparecimento da Documentação e da Ciência da Informação. Essa "disciplina científica passa a considerar Bibliografia, Biblioteconomia e Documentação como suscetíveis de aplicar os resultados de suas investigações" (ZAHER; GOMES 1972, p. 5). Pode-se inferir dessa afirmação que as autoras incluem a bibliografia no campo da ciência da informação.

Na visão de Hjorland, o estudo da bibliografia é amplo: inclui bases de dados, bibliometria e problemas relacionados à comunicação científica e acadêmica, além da história do livro (HJORLAND, 2007). Para falar sobre 0 campo de estudos, Hjorland cita o estudo analítico e sistemático de livros e outros documentos (FEATHER, 2003, citado por HJORLAND, 2007) que constituiria o coração da LIS, relacionando-se à organização do conhecimento, à recuperação da informação, à bibliometria. Referindo-se a Macevičiūtè \& Janonis, Hjorland destaca que o conceito de bibliografia se relaciona, por um lado, a um "trabalho tedioso de compilação" (HJORLAND, 2007) e, por outro, a uma disciplina revolucionária responsável por uma mudança paradigmática nas várias disciplinas relacionadas à informação.

Para Paling (2004, citado por HJORLAND, 2007), a bibliografia permite estudar a interconexão entre a classificação, a retórica e a disponibilização do conhecimento. O desenvolvimento da bibliografia teria surgido de forma concomitante à classificação para recuperação, destacando semelhanças entre problemas levantados pela retórica. Já para Mckenzie (1999), a bibliografia é uma disciplina que estuda a sociologia dos textos à medida que estuda textos como formas registradas, os processos de sua transmissão, produção e recepção. A bibliografia também se conectaria com a bibliometria e com a comunicação científica ao contribuir para o conhecimento da recepção de 
obras. Hjorland mostra que Otlet (1903, citado por HJORLAND, 2007) usou o conceito "ciência da bibliografia", e que inúmeros cursos foram denominados com o termo bibliografia, mas posteriormente tiveram suas denominações alteradas para Biblioteconomia.

Balsamo (1998) atribui a dificuldade de delimitação do campo da bibliografia tanto à generalização tardia do termo no título dos repertórios (século XIX), quanto à mais recente comparação ou atribuição da tradicional 'bibliografia' à Documentação, sem que esta tenha chegado a substituí-la. A história da bibliografia não poderia se limitar ao uso que se deu ao termo. Os fundamentos das teorias sobre a bibliografia no início do século XIX não aconteceram no domínio dos estudos, mas em função da própria necessidade de atualização bibliográfica e da especialização, bem como da frequência do termo bibliografia no título dos repertórios. O Repertório Bibliográfico Universal, de Otlet e La Fontaine, de 1895, mais os projetos do Instituto Internacional de Bibliografia, em Bruxelas, defendiam a Bibliologia como ciência total do livro, ciência essa que se subdividia nas áreas da história do livro, bibliografia (teoria, história, técnica, literatura dos repertórios) e biblioteconomia. Para o autor, a proposta não eliminou a ambiguidade léxica entre os conceitos porque superpôs a bibliologia e a história do livro, embora os campos e as tarefas dos bibliotecários tivessem ficado definidas frente às dos livreiros e dos historiadores. Além disso, a área da bibliologia se manteve imprecisa porque tratou o campo da história do livro segundo um modelo positivista limitado aos aspectos tipográficos da produção editorial, sem abordar sua articulação com uma história da cultura.

Na perspectiva de Walter Greg e de livreiros com objetivos comerciais, o termo bibliografia foi atribuído à descrição bibliográfica voltada à transmissão do texto: enquanto no sentido estrito a bibliografia é dedicada à produção de repertórios, para a filologia interessaria o "estudo da transmissão material de documentos literários ou de qualquer outro gênero" (BALSAMO, 1998, p. 182). Prevaleceu, nessa visão, a preocupação com o estudo dos textos literários escritos no sentido de estabelecer sua autenticidade, sua forma original e seu significado. 
Em resumo, a bibliografia é considerada, por Balsamo, "um dos campos de atividade do complexo sistema de comunicação social" (BALSAMO, 1998, p. $11,13)$ que se dedica aos repertórios, mas tem seus limites questionados em razão de sua natureza ligada ao livro. Ela ainda exerce seu papel, mas o faz a partir de outras formas, por exemplo, os abstracts, cuja origem remonta à própria bibliografia. Para Ortega, a Ciência da Informação mostra uma clara continuidade a esse campo.

Para Rino Pensato (1994), a bibliografia é um gênero literário ou documental que teve seu desenvolvimento a partir do trabalho de Gesner, cujo método compreendia desde a especificação dos motivos, objetivos e finalidades do registro, até o propósito de realizar relatórios consistentes. $O$ método, para Gesner, não significava tornar as coisas difíceis mais fáceis, mas de verificar que o problema da ordem e da racionalização em bibliografia é, definitivamente, o problema de seu significado cultural e de seu fim último: o de ordenar a produção da literatura por categorias constantes, reconhecíveis, científica e culturalmente relevantes e funcionais para a pesquisa, com fins de informação, localização e orientação (PENSATO, 1994, p. 13).

A teoria e as indicações de uma metodologia partiam da delimitação de finalidades culturais e, em seguida, técnicas, para a coleta, identificação, descrição e recuperação de informações. Considerando o método, seria impossível definir ou pensar na bibliografia hoje sem realizar sua reconstrução histórico-cultural ou, como afirmou referindo-se a Serrai, "o problema histórico e o problema teórico estão [..] intima e indissoluvelmente conectados" (SERRAI, 1985; 1988, citado por PENSATO, 1994, p. 14). A polivalência semântica do termo bibliografia deve ser atribuída não a uma característica de riqueza vocabular, mas ao resultado de uma alternância de léxico-conceitual das disciplinas relacionadas ao livro. O autor cita o trabalho de Blum, de 1969, relativo à variedade de denominações, que teria começado por questionar a própria origem grega da palavra bibliografia cujos radicais (biblio e graph) teriam tido outros usos e sentidos.

Pensato fala de Stokes, para quem "a bibliografia está em torno do livro" e "qualquer coisa que forme parte do livro considerado como livro é assunto da bibliografia" (STOKES, 1969, p. 407, citado por PENSATO, 1994, p. 16). Isso 
levaria à necessidade de não ignorar a natureza dupla (ou tripla) desse objeto que é, "às vezes, suporte físico de signos registrados, produto material de uma série de atividades tecnológicas, artesanais e artísticas, e veículo ou memória de mensagens, ideias e informações" (PENSATO, 1994, p. 16). Essa característica seria uma matriz de acepções de disputas no campo bibliografia entendida como ciência do livro enquanto objeto material, de um lado, e bibliografia como doutrina dos repertórios bibliográficos que servem à pesquisa e desenvolvimento intelectual, de outro -, mas também de uma constelação de significados e aplicações do termo.

O livro em seu conjunto, suas características físicas, as circunstâncias de sua aplicação, o gênero do discurso a ele referido, seu conteúdo semântico, o agrupamento de mais livros segundo um princípio a ele intrínseco ou segundo a finalidade são, segundo Serrai, "os pontos em torno dos quais se pode articular uma definição da bibliografia e uma distinção entre suas partes" (SERRAI, 1979, p.06, citado por PENSATO, 1994, p. 16).

Para Alfredo Serrai (2005, p. 313), a bibliografia seria, portanto, o sistema que articula as várias facetas de abordagem do documento. Ela é a teoria do sistema lógico que rege os processos de comunicação que ocorrem quando se utilizam arquivos da memória registrada. Considerada "mãe de todas as disciplinas" (ARAUJO, 2015), compreende aquelas que se envolvem com a organização e a comunicação escrita, cujos interesses se relacionam ao livro em seus distintos aspectos: material, tecnológico, editorial, comercial, artístico, relativo a colecionadores ou a bibliotecários. Engloba, entre outras, a biblioteconomia, a documentação, a arquivística, e é responsável pelo mapeamento da ciência e da cultura. Trata da organização do conhecimento (taxonomias, classificação e o que os italianos denominam 'enciclopedismo'), da catalogação (descrição de entidades, obras, autores, editores) e da mediação (realizada entre o mundo intelectual e o mundo das informações registradas), constituindo-se como metadisciplina, matriz disciplinar e um conjunto de práticas (ARAUJO, 2015).

A biblioteconomia americana não reconheceu a documentação a partir da justificativa de que as práticas as bibliotecárias perseguiam a mesma finalidade (posição de Shera). Bradford, por seu lado, afirmou a classificação, 
base principal da documentação, remonta à experiência das Pandectea, de Gesner (BALSAMO, 1998). O projeto da documentação de Otlet não excluiu a bibliografia, ao contrário, atribui a ela as bases técnicas de tratamento dos objetos da biblioteca, do museu, dos arquivos. Bibliografia e bibliologia não são opostas por Otlet, que trata as duas paralelamente, como se a primeira fornecesse fundamentos práticos para o que seria de natureza mais reflexiva, na segunda.

Na Colon Classification, Ranganathan (2006) distingue a bibliografia da biblioteconomia. O sentido de bibliografia em Ranganathan enfatiza o produto, razão pela qual ele propõe que os repertórios sejam analisados (e organizados) por tipo de documento (manuscrito, livro sonoro, impresso, filme, mapa etc.), por língua, pela natureza da publicação (livros, periódicos, patentes, teses etc), pela instituição publicadora, pela idade da publicação (antiga, corrente), pelo tipo de edição (primeira, de luxo, autografada etc.), pela agregação geográfica etc.

Ainda sobre a delimitação do campo, Hjorland refere-se a Stokes (2015, citado por HJORLAND, 2007), para quem o campo da bibliografia também se identifica com os estudos relacionados à bibliografia histórica, à bibliografia analítica, à bibliografia descritiva e à bibliografia crítica; a Dahlström, que relaciona bibliografia à crítica textual (DAHLSTRÖM, 2004 citado por HJORLAND, 2007) e à história do livro.

Difícil sistematizar a história da bibliografia. Muitos autores ressaltam a importância de relacioná-la à cultura, não só como algo que teve seu desenvolvimento acelerado pela imprensa, como pela exigência de difusão e comunicação no meio científico e acadêmico. Ainda do ponto de vista cultural, outros autores enfatizam a relação existente entre classificação, retórica, recuperação e disseminação do conhecimento. Outros, ainda, se preocupam com a relação entre a produção e sua difusão e recepção.

Há quem defenda um campo autônomo e veja como problemática sua subordinação à Documentação, bem como enfatize a ambiguidade léxica que resultou da superposição entre a bibliologia e a história do livro, limitando o campo deste último ao tratamento dos aspectos formais. Definiram-se, todavia, as atribuições dos bibliotecários frente aos livreiros e historiadores. Outros 
pesquisadores ressaltam que, além do sentido estrito do campo voltado à produção de repertórios, seria importante ressaltar os objetivos filológicos de estudo de transmissão material de documentos.

De um modo ou outro, na explanação dos autores consultados, o campo da bibliografia sempre está ligado à finalidade de dar conta da comunicação de livros e documentos. Compreende o produto material, a veiculação de mensagens, articula inúmeras facetas do documento e, na visão de alguns deles, engloba várias disciplinas e atividades capitaneando a tarefa de mapear o conhecimento.

\subsection{Bibliografia como Instrumento de Mediação}

A bibliografia é um instrumento de comunicação e enquanto tal instrumento indireto, mediador da organização e da ação social (EGON; SHERA, 1952, p. 125, citado por PENSATO, 1994, p. 38).

A necessidade de divulgação do conhecimento e as ações para alcançálas já existiam embrionariamente desde os tempos mais remotos via diferentes instrumentos. Listas de livros, repertórios temáticos críticos ou não referentes a coleções locais ou extramuros não teriam um fim em si mesmo, mas objetivavam a divulgação, mesmo para círculos restritos respondendo a imperativos culturais e institucionais, como também tecnológicos. Embora 0 objetivo da divulgação estivesse geralmente presente, é inegável que a imprensa permitiu o aumento do número de bibliografias e sua circulação. É sintomático que a obra de Gesner já visasse públicos amplos. Como afirmou Araújo, o método gesneriano conjugou memória bibliográfica e mediação, estabelecendo, assim um jogo entre monumentalidade e desejo de universalidade (ARAUJO, 2015).

Para Boodson (1976), o propósito das bibliografias e seu uso é a recuperação da informação. Para Zaher e Gomes (1972), desde o início, o objetivo da bibliografia era o de "divulgar o conhecimento acumulado nos livros", o que foi feito via repertórios de livreiros ou pelo trabalho de autores eruditos. Do ponto de vista histórico, segundo Balsamo (1998), a bibliografia mostra uma "[...] função institucional precisa, desenvolvida dentro do sistema de difusão da cultura". 
Há um outro tipo de mediação para a qual Balsamo chama a atenção, uma espécie de mediação negativa quando se observa a pouca atenção dada pela Bibliografia ao Index dos livros proibidos pela Igreja em meados do século XVI. Esse índice exerceu uma "finalidade institucional 'negativa"' (BALSAMO, 1998, p. 12) ao, paradoxalmente, impedir a circulação de determinados títulos. O Index teve um papel significativo na difusão da cultura no período da contrarreforma, e também depois, mesmo que ele tenha sido usado com funções opostas. No mesmo caso está a Bibliotheca selecta, de Antonio Possevino (1533-1611) que cumpriu funções de mediação positiva ao promover a circulação de certos livros, e negativa ao coibir sua circulação restringindo o número de livros aos títulos da "doutrina sã e purificada" (POSSEVINO, s.d., citado por BALSAMO, 1998, p. 65), desaprovando os considerados como meios "cultivados por Satanás para perturbar o cultivo dos espíritos" (1998, p.109).

As iniciativas dessas bibliografias se relacionam diretamente à formação das bibliotecas abertas ao uso público "nas quais encontraram aplicação diferentes cânones bibliográficos, determinados também por motivações ideológicas" (BALSAMO, 1998, p. 13). Em Gesner, o objetivo de transmissão da documentação cultural não se restringia aos públicos não eruditos, e quer sua bibliografia, como aquelas nela inspiradas constituíram instrumento de mediação importante ao responder a necessidades comerciais de livreiros e editores e a de informação bibliográfica, "em harmonia com o ideal humanístico que perseguia o lema "formar o homem livre de si mesmo, autônomo" (BALSAMO, 1998, p. 67).

Gabriel Naudé (1600-1653), numa postura não dogmática, definiu critérios e identificou motivações culturais para a bibliografia e a formação das coleções públicas nas bibliotecas antecipando, de algum modo, a função exercida pela enciclopédia. $\mathrm{Na}$ organização da biblioteca do Cardeal Mazzarino, Naudé defendeu a necessidade de adquirir todo tipo de livros, "porque uma Biblioteca criada para o uso do público deve ser universal" (BALSAMO, 1998, p. 71). Isso significava que uma bibliografia e uma biblioteca deveriam conter todos os principais autores antigos e modernos, as melhores edições e compilações, os melhores intérpretes ou comentaristas, os livros de 
hereges ou partidários de religiões novas etc. A seu modo, Naudé contraatacou os cânones e as práticas da contrarreforma e "propôs um cânone bibliográfico que é a expressão daquele novo clima cultural em que estava amadurecendo o Discurso sobre o método, de Descartes, publicado dez anos depois" (BALSAMO, 1998, p. 70). Assim como a de Gesner, a obra de Naudé constitui um manifesto cultural cujo objetivo era promover a circulação de livros sem nenhuma restrição quanto ao conteúdo, aos seus autores ou a seus leitores.

\section{A BIBLIOGRAFIA HOJE: CONSIDERAÇÕES FINAIS}

No século XX, a bibliografia entrou em crise, quer pela dificuldade de dar conta da produção que cresceu exponencialmente, quanto pelo surgimento de outros suportes diferentes do livro, o periódico e a revista. Isso não impediu, entretanto, que ela continuasse existindo ao lado do índice e do abstract, nascidos no seu seio (BALSAMO, 1998).

A continuidade da tradição bibliográfica em relação à atual ciência da informação aparece clara, sobretudo nos aspectos estruturais da formação e do uso da memória coletiva. A bibliografia é um mecanismo particular da memória secundária da informação, assim como as bibliotecas e os arquivos consistem em seções particulares da memória documental. A evolução tecnológica fez surgir, em ambos os campos, seus limites funcionais, devidos tanto à antiga técnica manual como à mecânica. Hoje são requeridos procedimentos e instrumentos adequados à tecnologia da automação, que ainda continua operando segundo um esquema estrutural fundamentado na recolha de dados, sua memorização e posterior recuperação. Este esquema esteve sempre na base da atividade bibliográfica e dele foram plenamente conscientes os bibliógrafos do passado, tal como se deduz do testemunho de Conrad Gesner (meados do XVI) (BALSAMO, 1998, p. 16).

De fato, o desenvolvimento da bibliografia se fez, ao longo do tempo, a partir de distintas práticas, conforme seus objetivos, orientando-se para a pesquisa, para fins pragmáticos ou para interesses dos livreiros. Um balanço geral sobre o tema e sobre sua pertinência nos dias de hoje requer combinar uma visão diacrônica, histórica, a uma abordagem sincrônica. Do ponto de 
vista diacrônico, podemos verificar que o tema bibliografia focalizou a produção de listas sob diferentes arranjos - bibliografias nacionais, internacionais, temáticas, retrospectivas, correntes, gerais especializadas; teve distintas motivações, atendendo interesses autorais, institucionais e histórico-culturais; exerceu diferentes funções: a divulgação, a comunicação e a mediação da informação. Do ponto de vista sincrônico, a análise dos produtos bibliográficos em si mostra elementos que respondem pelo desenvolvimento de metodologias de descrição, de representação semântica e, enfim, de organização de memórias bibliográficas que são objeto de apropriação e também de revisão, em face das tecnologias de informação e comunicação.

De início, as bibliografias foram conhecidas pelo seu organizador. A bibliografia tinha, numa linguagem atual, uma autoria. Esse papel aos poucos é dividido: liga-se a personagens que demandam repertórios, a mecenas. Em seguida, a autoria individual vai desaparecendo das bibliografias, com raras exceções e é transferida a entidades coletivas, ao Estado, a instituições públicas e particulares. A figura do bibliógrafo é dissolvida e praticamente desaparece no interior das instituições. Hoje, com o desenvolvimento das tecnologias de informação e comunicação há, de um lado, oferta de informações de todos os tipos via Google (por exemplo); de outro, a tarefa está a cargo de grandes empresas que selecionam, reúnem e disseminam informações a partir de critérios técnico-científicos, a exemplo da Web of Science, disponibilizada pela Thomson Scientific, da Scopus, pela Elsevier, ou de bases específicas, como a Library Literature Information Science Full Text (LLIS), publicada pela HW Wilson Company e a Library Information Science Abstract (LISA), editada e disponibilizada pela ProQuest, entre inúmeras outras.

A partir do Google, de repente, todos nos tornamos bibliógrafos - ou a produção de repertórios responde a demandas específicas e pretende-se que tenham respostas imediatas. Verifica-se, porém, que as estratégias de busca que utilizamos no cotidiano são, ou definidas a partir de uma expressão linguística ou, no máximo, recorrem a princípios simples de lógica booleana, razão pela qual para trabalhos mais densos temos de buscar assessoria. $\mathrm{Na}$ realidade, a atividade de levantamento bibliográfico tornou-se mais complexa 
exigindo a formulação de equações de busca sofisticadas, não só porque o número de publicações aumentou, como também porque as publicações reunidas em bases de dados de temáticas diversas usam metodologias de organização distintas e dispõem de diferentes recursos de busca e recuperação. Sistemas de Organização do Conhecimento diferentes - entre eles as linguagens documentárias mais conhecidas como os tesauros, os sistemas de classificação, as taxonomias - são adotados por cada base, cada um com seus critérios, idiomas, nível de especialização e de profundidade, tornando a busca complexa. Em determinados casos (como na área de Saúde) há bases de dados que utilizam vocabulários interoperados como um meio de compatibilizar várias linguagens de indexação, recorrendo à equivalência entre termos para poupar, ao usuário, o tempo de percorrer cada linguagem específica. Mesmo assim, não são menores as dificuldades para traçar estratégias de recuperação e organizar os resultados.

Mais raro é o caso das bibliografias críticas que, na maior parte das vezes, têm autoria determinada. Elas integram, geralmente, monografias acadêmicas voltadas a temas específicos ou, ainda, são consideradas preâmbulo de pesquisas mais amplas.

As bibliografias também são analisadas como instrumentos que realizam a mediação entre produção e públicos, ou mais exatamente, entre expressões em linguagem (representações) e seus públicos. Como nada é para todos, ou dito de outro modo seguindo as leis de Ranganathan, todo leitor tem seu livro, todo livro tem seu leitor, é necessário estabelecer a relação documentos públicos, o que demanda identificar elos de significação por meio dos quais as trocas entre emissão e recepção possam acontecer com mais acuidade. Os elos ou vínculos de significação se dão a partir de consensos, compartilhamentos, ou pontos de interesse comuns e são organizados a partir da definição de critérios ou hipóteses de organização. Eles são os recursos para orientar a agregação e a separação de documentos por operações de conjunção e disjunção, ou o estabelecimento de relacionamentos por valência semântica ou associação. (Por isso é tão importante a Pandectae, de Gesner, índice que complementou sua Bibliotheca Universalis e se antecipou às demandas dos usuários (ARAUJO, 2015). 
$\mathrm{Na}$ maior parte das vezes, a ordenação dos itens agrupados para facilitar a recuperação posterior persegue a semelhança, orientando-se pela lógica aristotélica que é auto excludente e pressupõe a crença em essências e a universalidade. O vínculo pela semelhança é orientado pela busca de uma divisão racional a partir de uma causa formal, derivando segmentações (SANTOS, 2010). Uma escolha à base da semelhança exclui outras escolhas possíveis. Os vínculos de adesão serão, consequentemente, relacionados à aceitação do critério utilizado para a segmentação. Se isso tem efeito em nível individual, é no nível social que ele se expressa com maior ênfase. As escolhas determinam as opções e as agregações possíveis. Por essa razão, o consenso torna-se a referência mais utilizada.

Outras lógicas procuram observar criticamente que o campo da experiência é sempre organizado a partir de culturas específicas, do que decorre a possibilidade de distintas formas de organização. Hoje, em torno do tema de organização do conhecimento acontecem discussões sobre a desclassificação (GARCÍA GUTIÉRREZ, 2011) como um recurso para fugir a lógicas reducionistas e pensar o pluralismo lógico como núcleo do processo de significação. Segundo essa perspectiva, a categorização considera a cultura como um sistema aberto e capaz de contemplar conceitos como construções dinâmicas distantes das demarcações rígidas e auto excludentes. Esse seria o meio de realizar uma mediação bibliográfica orientada para categorias mais flexíveis e que escapam aos preconceitos que marcam as classificações tradicionais. Experiências como essas mostram que as bibliografias são produtos culturais que, embora geralmente reflitam pontos de vista hegemônicos, podem também ter abordagens alternativas.

Propostas que buscam o pluralismo lógico derivam dos questionamentos contemporâneos ao modelo moderno de ciência, cuja emergência se deve à crítica dos usos e desusos da própria ciência. Questiona-se, hoje, não só a ciência, como adotá-la como forma privilegiada de organizar e ver o mundo, aumentando o interesse pela observação das suas dimensões sociais. Nessa perspectiva, os vínculos utilizados para gerar os índices são compreendidos como possibilidades de organização, nunca verdades.

A emergência de um modelo pós-moderno de ciência (SANTOS, 1988) 
também permite discutir a autonomia dos campos de conhecimento e, consequentemente, da Bibliografia. No seio das discussões sobre a crise da ciência, os limites entre os campos disciplinares estão borrados e, em seu lugar, são considerados mais importantes os empreendimentos inter e transdisciplinares. Mais do que as disciplinas, a ênfase é dada à definição de universos temáticos que congregam várias áreas do conhecimento pelo seu significado social. As abordagens inter e transdisciplinares, embora nascidas no âmbito das disciplinas, constituem tendências mais flexíveis e mais abertas a aceitar que os investimentos mais produtivos passam pela congregação de várias óticas. Importante, portanto, pensar seriamente se a disputa pela autonomia de um campo é pertinente no momento atual.

\section{REFERÊNCIAS}

ARAUJO, A. V. F. Pioneirismo bibliográfico em um polímeta do séc. XVI: Conrad Gesner. Informação \& informação, Londrina, v. 20, n. 2, p. 118-142, maio/ago. 2015. Disponível em:

<http://www.uel.br/revistas/uel/index.php/informacao/article/view/23127/pdf_62>

ARAÚJO, D. M. P.; REIS, A. S. Bibliotecas, Biblofilia e Bibliografia: alguns apontamentos. InCID: Revista de Ciência da Informação e Documentação, Ribeirão Preto, v. 7, n. especial, p. 183-201, ago. 2016. Disponível em: <http://www.journals.usp.br/incid/article/view/118770/116241>.

BALSAMO, L. La bibliografía: historia de una tradición. Gijón: Trea, 1998.

BOODSON, K. Subject bibliographies in information work. The Indexer, v. 10, n. 1, p. 15-23, abr. 1976.

BOUSTANY, J. Bibliologie, bibliométrie et bibliographie. 2007. Disponível em: <http://www.docinfos.fr/index.php/extrait-these/391-bibliologie-bibliometrieet-bibliographie>.

BRIET, S. Qu'est-ce que sais la documentation? Paris: Édit - Editions Documentaires, Industrielles et Techniques, 1951.

CAPACCIONI, A. La bibliografia: materiali per um esame comparato dei termini fondamentali. 2014. Disponível em:

$<$ http://iibi.unam.mx/publicaciones/282/problema\%20lenguaje\%20bibliotecologi a\%20La\%20Bibliografia\%20Andrea\%20Capaccioni.html> 
. Mapas y memorias: apostillas a una historia de la Bibliografia.

Documentación de las Ciencias de la Información, Madrid, v. 29, p. 09-24, 2006.

COUZINET, V. Fabrique de la liste: dispositif entre mémoire et commémoration. In: Jornada Científica Internacional Redes e Processos Info-Comunicacionais: mediações, memórias, apropriações (REDE MUSSI), 2, Rio de Janeiro, 2012. Anais... Rio de Janeiro: Rede Mussi, 2012. p. 132-149.

CRIPPA, G. A arte da bibliografia: uma pequena introdução. InCID: Revista de Ciência da Informação e Documentação, v. 7, n. especial, p. 03-06, ago. 2016.

GARCÍA GUTIÉRREZ, A. Pensar la transcultura. Madrid: Plaza y Valdés, 2011. p. 07-57.

HJORLAND, B. Bibliography. 2007. Disponível em:

<http://www.iva.dk/bh/Core\%20Concepts\%20in\%20LIS/home.htm>. Acesso em 12 ago.2015.

MCKENZIE, Donald. F. Bibliography and the sociology of texts. Cambridge: Cambridge University Press, 1999.

ORTEGA, C. D. O papel da bibliografia na construção do conhecimento em Ciência da Informação: o caso da Escola de Ciência da Informação da UFMG. Perspectivas em Ciência da Informação, v. 22, n. especial, p. 36-64, jul. 2017.

. O conceito de documento em abordagem bibliográfica segundo as disciplinas do campo. InCID: Revista de Ciência da Informação e Documentação, v. 7, n. especial, p. 41-64, ago. 2016.

PENSATO, R. Curso de bibliografia. Gijón: Trea, 1994.

RANGANATHAN, S. R. Colon classification. 6. ed. Bangalore: EES EES Publ., 2006.

SANTOS, B. S. Um discurso sobre as ciências na transição para uma ciência pós-moderna. Estudos avançados, São Paulo, v. 2, n. 3, maio/ago. 1988.

. Um discurso sobre as ciências. 16. ed. Porto: Afrontamento, 2010.

SERRAI, A. Brevissima introduzione ad uso dei neofiti (ma non solo) dei concetti chiave della bibliografia. Bibliotheca: Revista Di Studi Bibliografici, v. 4, n. 1, p. 313-320, 2005.

ZAHER, C. R.; GOMES, H. E. Da Bibliografia à Ciência da Informação: uma história e uma posição. Ciência da informação, v. 1, n. 1, p. 05-07, 1972. 


\title{
CONCEPT OF BIBLIOGRAPHY, OR CONCEPTS OF BIBLIOGRAPHY?
}

\begin{abstract}
Introduction: Bibliography is a polysemic term that covers products, activities, and an entire disciplinary field. Its numerous facets do not necessarily lead to a single, consensual concept. Objectives: This study seeks to discuss the concept of bibliography by examining the origins of bibliographical work, the relationships between the term, the concept and its definitions over time, its typology and mediation function, and reflections about the creation of an autonomous disciplinary field. Methodology: The present study was conducted using a bibliographical survey, comparing among the various reflections, and attempting to construct a brief systematization. Results: Although the denomination and concept of bibliography vary, there is relative consensus which states that the core meaning revolves around book repertoires and, more recently, documents in general. This definition emphasizes technical aspects of both librarian and book practices, as well as communication, sociocultural, and historiographic aspects. Some proposals that defend the autonomy of the field posit bibliography as a matrix discipline from which other related disciplines are organized. Conclusions: Bibliography is a special mechanism of secondary memory whose basic principle remains, in spite of technologies. It produces lists organized according to different arrangements and proposes description methodologies. The emergence of a postmodern model of science calls into question the appropriateness of the claim for an autonomous field, as this model favors an inter- and trans-disciplinary perspectives of thematic universes.
\end{abstract}

Descriptors: Bibliography. Concept of bibliography. History of bibliography. Information Science.

\section{CONCEPTO DE BIBLIOGRAFÍA, O CONCEPTOS DE BIBLIOGRAFÍA?}

\begin{abstract}
RESUMEN
Introducción: Bibliografía es un término polisémico que designa productos, actividades, además de un campo disciplinario. Sus innumerables facetas no conducen necesariamente a un concepto único y consensuado. Objetivos: Buscamos discutir el concepto de bibliografía examinando los orígenes del trabajo bibliográfico, las relaciones entre el término, el concepto y sus definiciones a lo largo del tiempo, su tipología y función de mediación, y las reflexiones sobre la constitución de un campo disciplinario autónomo. Metodología: Este estudio se basa en el levantamiento bibliográfico, la comparación entre las diversas reflexiones sobre el concepto, intentando construir una breve sistematización. Resultados: Aunque existe una variación denominativa y conceptual, hay relativo consenso sobre el concepto de bibliografía, cuyo significado central gira en torno a los repertorios de libros y, más recientemente, de documentos en general. Se enfatizan aspectos técnicos de las prácticas bibliotecarias y también libreras, como aspectos comunicacionales, socioculturales e historiográficos. Algunas propuestas de reivindicación de la autonomía del campo argumentan en favor de la bibliografía como disciplina matriz, a partir de la cual se organizan otras disciplinas relacionadas. Conclusiones: La bibliografía es un mecanismo especial de memoria secundaria cuyo principio básico se
\end{abstract}

Inf. Inf., Londrina, v. 23, n. 2, p. 127 - 151, maio/ago. 2018. http://www.uel.br/revistas/informacao/ 
mantiene a pesar de las tecnologías. Se caracteriza por la producción de listas organizadas bajo diferentes órdenes y por la propuesta de metodologías de descripción. La emergencia de un modelo posmoderno de ciencia pone en cuestión la propiedad de la demanda de un campo autónomo, cuando se prioriza el enfoque de universos temáticos a la luz de las ópticas inter y transdisciplinares.

Descriptores: Bibliografía. Concepto de bibliografia. Historia de la bibliografia. Ciencia de la información.

Recebido: 10.05 .2018

Aceito: 25.08 .2018

Inf. Inf., Londrina, v. 23, n. 2, p. 127 - 151, maio/ago. 2018

http://www.uel.br/revistas/informacao/ 